of the battle, perhaps at a moment when we need it most. We can afford to neglect no weapon, least of all one so tried and true. Let us see that it is used to the full.

\title{
REFERENCES
}

BRAILSFORD, J. F. (1943), Public Health, lvi, II7.

CHADWICK, H. D. (I927), American Rev. Twb., xv, 60I.

FELLOWS, H. H., (1934), Amer. J. Med. Sci., clxoxvili, 553.

FROST, W. D., (1937), Amer. Journ. Public Health

SIEGAL, W. (1940), Tuberculosis in Industry, New York, p. 301.

TRAIL, R. R. (1943), Public Health, lvi, II7.

TOUSSIANT, C. H. A. (1943), N.A.P.T. Annual Conference, London.

\section{MASS RADIOGRAPHY}

\author{
By JAMES F. BRAILSFORD, M.D., PH.D., F.R.C.P., F.I.C.S. \\ (Consulting Radiologist to the City of Birmingham Hospitals; Honorary Radiologist to the \\ Queen Elizabeth Hospital, etc.)
}

In his presidential address to the Faculty of Radiology in I94I S. C. Shanks (1) stated: "The war has brought into prominence a problem which many of us have been dreaming about, and have regarded as Utopian-that of mass radiography of the chest. As there is now some chance that it may in future be adopted on a large scale, and as I have been somewhat involved in its consideration, it might be of interest to you to hear something of the present position."

This propaganda fell on suitable ground-for the Minister of Health in I942 expressed some concern at the increase in the number of deaths from tuberculosis during the years I938-4I, i.e. from 26,176 in 1938 to 28,669 in I94I. The effect of the propaganda can be appreciated from the statements which he made in the House on June 30, I942. (2) He then indicated that we need to give greater practical effort to the necessity of early diagnosis. "We have tended tQ concentrate on treatment rather than early diagnosis, but the developments in miniature radio $\overline{0}$. graphy during the last few months seem to give us a new and useful weapon for detection-an $\$$ it was hoped that towards the end of the year we should be able to use radiographic units on $\dot{a}$ carefully planned basis. In this way I hope we shall be able to detect and treat tuberculosis in the early stages when we can, by a period of suitable treatment, restore a man to health and self-sufficiency with the shortest possible interruption of his normal life."

The medical journals, lay Press, and the wireless took up the propaganda, and for the most part refused to publish criticisms of the scheme, consequently the impression was given to the public that this miniature photography of the screen image, wrongly called miniature radiography, could be so applied to the whole population, that all cases of tuberculosis would be recognised early, and prompt treatment would result in marked diminution if not eradication of the disease.

It was pointed out by the advocates (3) that each unit could deal with some 300 cases per hour, or "4 per minute without undue fatigue," and that the interpretation of the miniature photographs could be done at a similar rate. Apparently no attempt was made to consider what these figures meant when applied to the population, say four times a year. The enormous number of units required and, even more important still, the number of trained medical and lay staffs and accommodation in normal times, would alone have sufficed to check the enthusiasm of any advocate. The degree to which the mentality was affected by war panic in this blackest period of our history can be measured by the fact that at the time the scheme was launched we probably had the greatest relative poverty in equipment, medical and lay personnel, and accommodation in our history. To do the whole population at three-monthly intervals, with the saner rate now advised, we should need the accommodation and personnel for something like 4,000 units. No treasury in peace time would countenance such prodigious expenditure on one aspect of public health when so many call for attention. Since the publication of previous criticism by the author (4) and (5) the "Advisory Report on the working of a Mass Radiography Unit," "to give practical advice on the establishment and operation of the scheme for mass miniature radiography" has been issued, and in this paper attention will be given to the points raised in this report of the sub-committee of the Standing Advisory Committee on Tuberculosis. 
"These miniature films," the report states, "indicate sufficiently to a trained observer whether the chest is normal or whether some abnormality is present, the nature of which should be determined by full investigation." This statement alone exposes the fallacy of the whole scheme. In a later paragraph the question, who constitutes a trained observer?, will be discussed.

No radiograph with the best technique available (and as I have shown (4) the miniature photograph of the screen image is much inferior) will show whether the chest is normal. The radiographs of but a small proportion of patients found by the medical practitioners to be suffering from chest conditions and referred by them to Tuberculosis Officers, Consulting Physicians, or Radiologists, show any recognisable evidence of tuberculosis or other disease. The claim of the report suggests that the onset of a lesion is registered as a radiographic sign-a claim which is most misleading. Those who have made a comparative study of the macroscopic and radiographic appearances of pathological changes in the tissues are impressed by the extent of the changes necessary to produce recognisable radiographic characters. Some of the advocates have admitted that lesions large enough to be associated with the spitting of tubercle bacilli have not been recognisable on direct radiographs of good quality. No wise physician would be prepared to accept a chest as normal merely because the radiograph showed no abnormality, particularly when he has no knowledge of the patient's history, and has never seen the patient, nor heard of his condition. It was stated in the House by Mr. Bevin, (6) respecting the death of a case of tuberculosis, the diagnosis of which had been missed,. "The investigation of previous medical history forms an important part of the medical examination, which includes careful questioning on this matter by the examining doctors." Yet here we have a measure which completely excludes these factors. As to the advisability of determining by full investigation, the nature of some abnormality shown on the radiograph of a patient, who is apparently well -i.e. happy in his work and play - we have to realise that treatment or avoidance of it should be determined by the condition of the patient. To submit a patient with no clinical signs or symptoms to an extensive investigation, which probably yields no further information, is to create very considerable distress in the mind of the patient and his relatives. Further meddlesome interference with symptomless lesions has resulted in producing disabilities and in some. cases has led to the death of the patient.

In assessing the value of the radiographic diagnosis the following points must be taken into account:-

(I) It has been repeatedly proved that a patient may be spitting tubercle bacilli while a radiograph at the time may show no departure from the normal.

(2) There are lesions which produce radiographic appearances indistinguishable from those of tuberculosis and which disappear within two months without leaving any sign of disease.

(3) The single examination in many cases gives no idea whether the disease is active or healed: it may not be possible to determine this without a very prolonged investigation.

(4) Tuberculous lesions shown at one examination may be absent after an interval of six months.

(5) In a fair proportion of cases the radiographs will have to be repeated because they are unsatisfactory for diagnosis on account either of an increase in the shadows, or of a technically defective radiograph.

(6) A patient with clinical signs and symptoms of pulmonary disease may have a normal radiographic appearance.

The importance and significance placed upon the radiograph is emphasised by the following statement: "Since the sifting is based upon the radiography of the chest, the further diagnosis will be directed to chest conditions, in general to tuberculosis and other affections of the lungs and to cardiac abnormalities."

The advisors would use this inferior type of screen image as a sifter, and have claimed that by it such conditions as advancing pulmonary tuberculosis, pleural effusion, empyema, pneumothorax, aneurysm and neoplasm were detected in apparently healthy persons, though such lesions had been unsuspected and missed at careful clinical examinations. One enthusiastic advisor stated that, though a series of direct radiographs of normal size were regarded as normal, miniature photographs of the screen images of these patients revealed easily recognised lesions. It 
was stated in (7) The Lancet in a leading article, without any explanation as to why the discrimination should be so favourable, "The pathological changes overlooked in the miniature, such as calcified glands, were all unimportant, whereas changes of clinical significance were always detected."

Support of the view that the radiograph does supply evidence of tuberculosis in patients who have been medically examined with negative results is furnished by E. C. Cooper. (8) He instances three cases in his series, the first of which is as follows: "A man serving in a medical unit was passed fit, Class $\mathrm{I}$, at two medical examinations, yet X-ray examination showed extensive chronic tuberculosis with large cavities on both lungs. The sputum contained tubercle bacilli. On being questioned he admitted he had been under treatment for tuberculosis for the past three years. Cases 2 and 3 were also passed as fit at the medical examinations, yet on questioning following positive X-ray findings, histories of blood spitting, recurrent pleurisy, etc., were obtained." One is tempted to ask, what is the standard of clinical investigations which fail to reveal such lesions? Certainly, if it were true that such conditions could be discovered by radiography only, then the sooner the expense of the medical examination is cut out and the best radiographic service substituted the better.

The type of radiography to be used in the scheme is not as good as that used some years ago when clinicians would not accept the radiographic findings which were opposed to the opinion they had formed at a clinical examination. We were then taught the importance of the clinical history, physical signs and symptoms, and expected to diagnose the patient's condition on these, for radiography was not universally available. Why this voite face? In my opinion it is due to the fact that the atrophy of disuse is affecting the clinician. Whereas the clinician who has carried out a thorough clinical investigation of his patients is selaiom shocked by the radiographic appearance of the patient, those who have made a hasty examination are so frequently shocked that they seek refuge in early radiograpbic examination, avoiding or neglecting the preliminary clinical examination; though they may subsequently discover the clinical signs to support the radiography. It is probably because of this that there is a growing tendency to treat the patient's radiographic appearances which he thinks he understands, rather than his clinical condition which he has not investigated. This is recognised by the radiologist, who, contrary to the views of some, has learnt a very healthy respect, and perhaps no small ability? for good clinical investigation, having been repeatedly disappointed at the limitations of radiographic interpretation. The radiograph heeds no speciality, it is but a measure of the relative densities of the tissues traversed by the X-radiation, and this includes the skin on both sides of the area radiographed, together with any structures on or in the skin, and the contents of the whole thickness of tissue between the skin surfaces. These conglomerated shadows of all the tissues are condensed into the thin plane of the film. Certain variations in any or all of these structures affect the radiographic appearances, and it is the failure to appreciate these truths that causes the observer with little radiographic experience, whatever his reputation in the clinical field may be, to fall into the many pitfalls of interpretation. Operative measures have been conducted on radiographic appearances recognised by the radiologist as normal or incapable of producing the symptoms of which the patient complains. Many ill-considered demands (4) and (5) are made on the radiographic departments, and as the uselessness of these is recognised by the radiologist, interest in the cases is lost and the radiology suffers.

The report acknowledges that "if the radiography is not of a high standard the consequence will be either that too many cases will be reported as abnormal, which will cause unnecessary waste of working time, unnecessary skilled work in the subsequent diagnosis, and unnecessary alarm to the persons concerned, or, on the other hand, cases of early disease will be classed as normal and the disease allowed to develop until the symptoms are more patent and the disease more untractable." "Radiography of the chest is in any case a process that requires for satisfactory results good apparatus and a skilled radiographer." Note here the emphasis which is put upon the radiography. I will agree that bad radiography may produce such results in the hands of those who are not trained in radiology, but the trained radiologist would appreciate the poor standard of the radiography and reject that likely to lead to misinterpretation. His superior knowledge of radiography and its interpretation should enable him also to detect artefacts due to faulty technique. This brings out the essential point, that the success of the scheme is entirely dependent upon the interpretation of the radiographs. 


\section{The Team and Its Work}

When the mass miniature photography was first urged upon the Ministry of Health the numbers which it was stated (1) could be photographed per hour was in the nature of 200, "or flat out 300 cases per hour," but since the adoption of the scheme the numbers quoted have gradually diminished, and in the report one is considering it states, "The number that can be dealt with by a single team is perhap $\mathrm{I}, 000-\mathrm{I}, 200$ a week, or $\mathrm{I}, 500$ working under some pressure." The team consists of a Medical Director, a Consulting Radiologist, a Radiographer M.S.R., a darkroom technician, two clerks, and one marshaller. If 2,000 are examined per week the nonmedical staff to be doubled, and "if the work of the unit becomes very heavy, it might be necessary to appoint a Deputy Director to take part of the work." Note that the non-medical technician-the radiographer, must have the M.S.R., but no such qualification is required for the person who supervises his work. The Medical Director has no radiological qualification other than that "he should be a physician experienced in the clinical and radiological aspects of diseases of the chest." Nevertheless some of the advertisements for the post, which require so much for so little, have stated that the person appointed may be required to do any other radiological work. "The Consulting Radiologist should be part-time only, and must have had considerable experience in the radiological examination of the chest, should preferably be associated with a University. His duties should be to advise on interpretation and technical procedures" the report reads, but one gathers from the following statement, "He must in each unit inspect a sufficient number of films to keep a check on the radiographic quality turned out by the unit," that he is to be but a consulting radiographer.

\section{Reading of the Films}

"Interpretation of the film is, strictly speaking, a matter of pure X-ray diagnosis, and in those cases, therefore, in which the clinician to the unit is not skilled in X-ray interpretation, the reading of the film should be undertaken by the radiologist alone." Having stated this truth so emphatically, the report goes on to state, "Normally, however, the Medical Director should have had considerable experience in interpreting chest films, if so, he should take the major part of this work." If his unit undertakes anything like the 5,000 cases per week suggested by the Minister, how can he possibly do much else than radiography, and how long would he be considered a physician experienced in the clinical aspects of the diseases of the chest.

In a previous paper (5) I stated, "As to the personnel for each unit, some authorities have stated that it is necessary to have both a radiologist and a chest physician in the team. Dr. Trail has expressed his opinion that only a competent chest physician is needed in addition to the technical and clerical staff. (This suggestion has been embodied in the report in question.) Personally, I cannot understand either view. I believe that co-operation of clinician and radiologist is most desirable: each has presumably acquired a knowledge in the sphere of his activities which is superior to that of the other, and it seems reasonable to expect that united they would give a sound opinion. Seeing, however, that under the scheme proposed for use in this country the clinician does not see and examine the patients before the radiographs are judged, he cannot make his proper contribution to the interpretation." In other words, he is redundant. As already indicated, the essence of the scheme is obviously radiographs and their interpretation: any preliminary clinical investigation is vigorously and to my mind foolishly excluded. Yet in spite of this the report states, "The responsibility for classing a miniature film as 'normal' or 'abnormal' should not rest with the team but with one individual-who should normally be the Medical Director."

Would it not have been more rational to have left this sphere in the hands of an experienced radiologist (if it were possible to find such men willing to do it) and have reserved the clinician to investigate those cases set aside for clinical examination. For note the report states, "The first step in the further examination of a case in which the miniature film shows some abnormality is to take a full-sized skiagram." Who could decide on the necessity for the direct radiograph and its interpretation better than the radiologist?

To combat possible criticism from interested specialists, loose statements are made in the report such as "it is highly desirable that other specialists should take part in the examination of the films so that their skill and experience may be used in the work." "The local Tuberculosis Officer should be invited to help in the examination of the miniature films and in the 
examination of the large films taken of abnormal cases." "The one person reading the film should consult the radiologist in any case of doubt."

Well may one ask, what constitutes a case of doubt? Surely not the well-established case of pulmonary tuberculosis, for the student is taught to recognise the appearances of the typical case. On the other hand, experience and knowledge are very essential to pick out the first signs of disease, i.e. to sift the normal. The clinician, if he is made responsible for any cases missed will find this task far more difficult than the experienced radiologist, for he will have no evidence of the clinical history or condition of the patient to guide him, little or no knowledge of radiographic technique and its many fallacies, and a relatively small experience in general radiographic interpretation.

\section{Responsibility of Medical Director and Radiologist}

Analysing the findings of 53,400 X-ray films of men in the Army of the United States, Esmond R. Long and William H. Stearns (9) state: "This review would indicate that a certain number of active cases slipped through-a certain number could easily be missed unless one inspected the $4 \times 5$-inch views singly as well as stereoscopically. More difficult to explain is the overlooking of several cases of moderately and far advanced disease." In the discussion which followed the reading of the above paper Colonel de Lorimer stated (10) that "each mistake cost the taxpayers \$10,000-\$15,000. Moreover, in many instances there was dissemination of the disease by the individuals involved, resulting in a multiplication of the compensation requirements. Surely these studies indicate the great responsibilities which rest upon doctors who are entrusted with this work."

E. G. Ernst, (11) who followed, said: "Let us not be unmindful of the mental anguish and economic stigma which will most certainly follow many of these rejected applicants throughout their lifetime. In a group of 24 men observed during the past month and examined by me 3-5 years previously, prior to their present examination, all of whom were rejected by Army Boards as tuberculous subjects, not a single one presented suspicious history findings, and even now they show no evidence of clinical tuberculosis."

It will be apparent from these quotations that even with the ideal conditions of Army service errors of omission and commission are made, and whoever takes over the interpretation must be aware of his responsibility, and the possibility of his errors being discovered at a further examination. In our scheme it is the Medical Director who must shoulder all the responsibility. How the radiologists concerned managed to evade this and the routine interpretation is difficult to imagine. Nevertheless it is my opinion that as long as the Government wishes these units to be in operation it is clearly the duty of radiologists to see that as high a standard of technique and interpretation is maintained as possible, and to render all the service they can under the circumstances. We know from experience that the sifting of normality from the early case of disease is a difficult task, and when hundreds of such films have to be judged conscientiously for an hour or so on end, fatigue sets in insidiously and warps our judgment. Repeated day after day on the scale suggested by one of the advisors, "the number of 200 per hour should be regarded as the optimum," judgment would not fail to be affected by boredom. The report admits that "the task is a somewhat tedious one." On the other hand, the periodical inspection of units and their productions may be a pleasant task for the travelling advisor, whether he be clinician or radiologist. We radiologists cannot evade our responsibilities in the way suggested by one leading radiologist, who wrote: "I am in favour of mass radiology, but I don't think it can be applied to the whole population, and I should hate to be one of the interpreting radiologists, even if it only meant four hours a week," and in a further letter: "I think this work would be so monotonous that very few people of real ability would care to take it up."

\section{Propaganda}

If we examine the mortality rates from tuberculosis (2) we find that there was a steady decline during the years I9I6-I938-whereas in I9I6 the number of deaths was 53,858 , in I928 it had been reduced in the 22 years to 27,176 , i.e. one-half. The reduction was brought about by the workers in public health and hospital organisations educating the public to the danger of infection from cases of phthisis. The success of the measures indicate that they were founded on right principles. In this meritricious radiographic scheme, which appears to 
have,attracted many unthinking supporters mainly by its spectacular character, the infectivity of the disease appears to have been overlooked. The increase in the number of deaths to 28,669 in I94I was not due to failure in early diagnosis, but to the introduction of persons spitting and coughing up tubercle bacilli into black-out conditions of life when susceptibility was induc-d by overcrowding, lack of ventilation, fatigue, distress, deficient foodstuffs, cold, dampness, and the increased difficulties in medical practice from reduction in the medical practitioners and the longer hours of the workers.

It has been stated that there are at least 50,000 persons going about spitting tubercle bacilli who have not been diagnosed, but it must be realised that there are probably more than this who have been diagnosed and treated yet are still spitting and coughing up tubercle bacilli. The obvious thing to do would be to find out who are spitting up tubercle bacilli and by further education teach them not to infect others. From periodic radiographic examination of the whole population, say every three months, we should get to know the location of all those who have radiographic evidence of tuberculosis with the limitations indicated in a previous paragraph, but this knowledge will be useless unless it is associated with efficient treatment and education or, as some would suggest, compulsory segregation. Now we have neither the medical nor nursing personnel, equipment nor accommodation to treat those we already know. We certainly have no means of controlling those we know to be infectious: the scheme under consideration does not encourage the chronic infective persons to stay away from work by allowances-he is forced to mix with his fellows to get a living. Only those who appear to the Medical Officer likely to benefit from sanatorium treatment, and will return to work after, are to be given allowances. Segregation of all the infected would be impossible. It is unlikely that the public would agree to any form of compulsory segregation of the infectious, even if these could all be discovered, for the patients who have been temporarily "cured" may at any time break down and again become infectious. If the complete scheme would be unlikely to yield the desired effect, how can we expect to derive any. material benefit from the examination of relatively small groups? No one would think of examining merely isolated groups of a certain age period or in a particular trade or profession in an epidemic of smallpox, ignoring all the multitudinous contacts - some of whom would undoubtedly infect normals in the groups examined. To carry out the-investigation on relatively small numbers of the population, as can only be done with the few units available-except, perhaps, in the gaols or asylums where the outside contacts are few and not intimate-could not be regarded as a useful measure in preventive medicine. Even in the Services, with their close segregation, which permits of multifarious outside contacts not subject to inspection, the investigation must be conducted at least every three months to detect cases infected from outside, otherwise they would become foci of infection, the more dangerous because of the false sense of security given by the radiography. To impose it compulsorily, as suggested by some enthusiasts, on groups of workers, ignoring all contacts, would not be a contribution to preventive medicine, but would be an unjust penalisation of the selected workers who happened to be so unfortunate as to be examined. How unfortunate is indicated by the aims of some officials. For instance, A. G. Evans states (13) of the infected patient: "This type of patient should never be re-employed in an indoor industry, however well he may feel in himself, except in a light sedentary job where he has an office to himself. The fact that a patient has become temporarily sputum negative is no guarantee that he will not again become sputum positive under conditions of stress. One envisages that in the future there may be some form of industrial segregation of this type of case in the big industrial areas so that they can be usefully employed in indoor industry. It is only by such bold measures that we can hope to tackle efficiently the problems before us." "It is hoped, and anticipated, that a considerable proportion of these cases, having been discovered in an early stage, will be suitable for artificial pneumothorax, which, after preliminary induction in a sanatorium, can be continued at a local tuberculosis dispensary." It is certainly not inviting to think that all the patients with minimal lesions will run the risk of being given such prolonged and probably unnecessary treatment with artificial pneumothorax. These group examinations might be used for the much less worthy purpose of excluding the unfortunate victims of the disease, whether active or healed, and those unlucky enough to be dubbed suspicious, from certain industries and professions, from certain insurances and superannuation benefits, and from desirable social contacts, or even as a measure of the efficiency or efficacy of the medical examinations in any particular area. The poorer the standard of medical examination, the greater the number of cases discovered by radiography, and conversely, the better and more complete the medical examination 
the less the number of radiographic discoveries. The report states, "mass miniature radiography, if applied to large sections of the population, will afford a body of information on the incidence of disease of the chest that has never been available before." Surely it cannot give us as much information respecting these conditions as we could obtain from an investigation of the case $\stackrel{\mathbb{Q}}{\mathcal{Q}}$ histories of such patients who have been more carefully clinically and radiologically examined $\subseteq$. by experienced physicians and radiologists during the past 25 years in our large hospitals. The $\overrightarrow{\vec{F}}$ propaganda suggested throughout the report indicates mass deception of the population, rather $\stackrel{0}{\rightarrow}$ than education. which during the past 25 years has reached a far higher standard than the advocates of the scheme appear to appreciate, and, as already stated, has resulted in halving of the death-rate from tuberculosis. The report states:-

"It is important to avoid creating the impression that mass radiography (I) is intended $\mathbb{\mathbb { D }}$ for those already ill, or (2) that there is danger in his condition of work or life, With reference $\%$ to (I) we are told in the same paragraph, however, that "It is at this stage that ignorance of the $\vec{\circ}$ condition means risk of permanent incapacity or of premature death." Surely such conditions $\stackrel{-}{-}$ would not be without influence on the patient or without signs for his doctor. There must be $\vec{\omega}$ relatively very few of them in apparently healthy people which will be discovered by radio- $\stackrel{\rho}{\circ}$ graphy only. Further, is not the whole scheme based on the suspicion that there is much $\underset{B}{7}$ more tuberculosis and disease than we already know, and doesn't this mean therefore that 3 everybody is suspected? With reference to (2), it can be said that the person concerned will i have a good idea whether there is danger in his condition of work or life. It may not be thought in to be in the best interests of the employer to give the impression to the worker, that the work $N$ is dangerous, but I cannot see that the workman will object to any investigation which proves $\vec{\omega}$ it. My impression is that he will be more satisfied if he knows his danger. Workmen do not $\mathrm{G}$ object to an X-ray investigation to substantiate a claim for silicosis.

$I$ (12) advocated in I937 that radiographic examination of the lungs of persons about to $\rightarrow$ commence any occupation likely to cause damage to his lungs was a humane course, and that $\bar{\jmath}$ this should be followed up with periodic radiographic examinations so that on the earliest sign 2 of damage he could be transferred from the work and so saved from the protracted disabilit $\vec{\omega}$ and earlier death which comes from continuation. This periodic examination is importan because only a proportion of the workers are affected. From the public health point of view no. workman or reasonable employer is likely, or should be allowed, to object to any measure whic detects early signs of danger from work and permits of preventive measures being adopted. Yet we see in the report: "It (the approach) must not be made through the employer only, or suspicion may be aroused on the one hand, that the examination is offered in the interests of the employers, or on the other hand, that the particular employment has special dangers which make examination particularly necessary. In particular, any attempt to make examination a condition of employment must be discouraged until the idea of routine examination of persons apparentlyhealthy is more generally accepted as a normal and sensible precaution."

\section{Summary}

The scheme of mass miniature photography of the screen image is anything but Utopian. It is inferior to modern direct radiography; it is attractive chiefly because of its spectacular $\frac{3}{6}$. character. Because it is used as a sifter before any clinical investigation, even if applied to $ᄋ$ the whole population every three months, it would miss cases, and without total compulsory $₹$ segregation of all the infectious (almost an impossibility) it would not make any material contri- 윽 bution to preventive medicine and its cost in medical and lay services, equipment and accommo- $\rightarrow$ dation would be out of all proportion to its benefits, and to the expenditure in other social o services of equal importance. It would be less effective than the unspectacular but more $\bar{N}$ practical examination of the sputum or of reasonable extension of present services. It is an $\Omega$ anti-social measure which could never have been adopted had full criticism been permitted at $N$ a time free from the panic of war.

\section{SUGGESTIONS}

A careful examination of all the features of the scheme will reveal that we have neither the skilled personnel, equipment, nor accommodation necessary to radiograph the whole $\stackrel{\mathscr{N}}{\rightarrow}$ population. We have not sufficient of any of these to treat the cases found in the present system. 0 Even if all the essentials could be obtained we should not detect all the infectious persons, and $\underset{\mathbb{D}}{\stackrel{\circ}{*}}$ 
the expense and labour necessary would be out of all proportion to what is spent on other equally important matters, and unjustifiable seeing that its findings could not be taken advantage of without compulsory investigation of the whole population and compulsory segregation of all the infected or suspicious.

If mass examination of the population is necessary, then why not mass examination of the sputum? I know this has not the spectacular features of mass radiography, but it is at least as accurate and would tell us the more important facts, i.e. who are actually putting out the tubercle bacilli, without which we cannot contract tuberculosis whatever the debilitating circumstances. Mass sputum examination could be carried out by a team of boys or girls with trained overseers acting and working under the general supervision of a bacteriologist. It would not even be necessary for the latter to have a medical qualification. I prepared and examined for tubercle bacilli hundreds of specimens of sputum picked up from the pavements of the City and from the floor of public conveyances by court cleansers under the direction of the late Sir John Robertson, long before I had a medical qualification, and on these findings a bye-law to prevent spitting in these places was secured. Such an investigation could be done with the minimum disturbance and loss of time of the worker and at relatively little cost. It certainly would not lead to the mental disturbance of mass radiology, particularly in those with symptomless healed lesions, and if nothing more was done it would permit of the education of the infectious person-the most essential teaching for the eradication of the disease.

What is wrong with the present methods which have already achieved so much? It has been stated that there are tens of thousands of people spitting tubercle bacilli who have not been diagnosed (there are probably quite as many who have been diagnosed), and that this is due to the symptomless nature of the disease which has been missed by the doctor. I suggest that this could be remedied by giving the practitioner facilities for getting the essential laboratory and X-ray investigations. . Relatively few patients with chest symptoms have active tuberculosis and abnormal radiographic appearances-one cannot be surprised that after numerous references to tuberculosis clinics with negative reports the practitioner becomes sensitive and chary of seeking further advice. And it is not only the practitioner who tires. The tuberculosis officer, periodically examining contacts, gets to the stage when he feels that with so many negative examinations he can let a contact go with the instruction that he is to report if symptoms develop; therefore why not give others the same freedom from investigation until symptoms develop? It is probably within the experience of all that such a relatively free contact may turn up 5-Io years after with extensive disease.

The miniature photograph of the screen image supplemented by sputum examinations as indicated I suggest is the solution to the problem. Instead of using these units as advised in this report, they should be used for the examination of the suspected, the repeated examinations of the contacts, and the men engaged in occupations liable to injure their lungs. Instead of adding to the financial burdens of the country, this would lessen them, as the expense in films and apparatus would be minimal.

The number of units provided by the Government would probably be adequate to deal with the whole country, for arrangements could be made in county towns to examine the patients from the surrounding smaller districts. The examinations could be readily obtained, and the practitioner could be given every encouragement to refer all his chest cases, if necessary repeatedly, at little cost.

\section{REFERENCES}

(I) SHANKS, S. C., British Jour. Radiol., I94I, Feb., 45.

(2) Parliamentary Debates, I942, V. 381, No. 82.

(3) CLARK, K. C., CORDINER, G. R. M., and ELLMAN, P., Brit. Jour. Rad., 194I, Feb., 54.

(4) BRAILSFORD,' JAMES F., Med. World, I942, , 5777

(5) Ibid., Public Health, I943, July, LVI, Io.

(6) BEVIN, E., The Lancet, $194 \mathrm{I}, 2,203$.

(7) The Lancet, $1941,2,287$.

8) COOPER, E. C., Brit. Med. Jour., 1940, 2, 245 I.

(9) LONG, ESMOND R, and STEARNS, WILLIAM H, Radiology, 1943, Aug., 144

(Io) LORIMER, COLONEL 52, ibid.

(II) ERNST, E. G., ibid.

(12) The Medical Annual, I939.

(13) EVANS, A. G., Brit. Med. Jour., I943, 1, 565. 